Measurements for Stresses in Machine Components

By V. F. Yakovlev and I. S. Inyutin; translated from the Russian by J. J. Cornish. Pp. xv + 135. (Oxford, London and New York: Pergamon Press, 1964.) $50 s$.

$\mathrm{W}$ HILE this text has all the signs of careful and reliable translation, it remains a somewhat slender and in some respects ill-balanced treatment of experimental stress analysis. The authors support their discussion by 69 reasonably well-chosen illustrations (mainly line diagrams) and 43 bibliographic references-almost entirely selected from Soviet publications. Though a useful book for engineers and research workers deeply concerned with the strength of structures and machine components, it has little general appoal as a teaching text, and the publishers rightly claim no more than that it ". . . will be of interest in graduate departments of engineering ....".

It is not unduly purist to point out that, despite the title, the book is concerned with the more familiar situation, namely, measurement of strain and subsequent inference of stress. The central theme is devoted to techniques, based predominantly on the electric resistance strain gauge, for assessing the distribution of stress inside solid bodies: the greater part of the text deals essentially with static loading, but the final chapter touches briefly on dynamic and impact conditions. The technique requires that unbonded strain gauges-sufficiently small and close together to justify the assumption of measure. ment at a point-should be embedded in models (not necessarily full-scale) cast in epoxy resin. Practical aspects are discussed in considerable detail, covering manufacture and positioning of the gauges themselves, appropriate electrical measuring circuits, correct treatment and curing of the resin, together with advice on materials suiteble for the moulds. Illustrations of how the procedure may be applied are then given in terms of simple bending of beams, stress concentration at a circular hole in a flat-plate, two mutually perpendicular cylinders which are pressed against each other, and the pressure of variously shaped dies on an elastic half-space. Mathematical analysis is used somewhat sketchily and it is probably at this point that workers having only a limited background in stress analysis will find the book unsatisfactory.

Although the opening chapter ranges over most basic methods of experimental stress analysis, much discussion is superficial. In particular, scant attention is paid to the process of inferring the magnitude and axes of principal stresses from surface strain gauge observations. This particular inadequacy runs through to the main theme of the book; and the inexperienced reader is left much in the dark on how exactly to infer principal stresses at a point where he has no prior knowledge whatever of the axes of the principal strains.

However, despite its weak points, this book will be of interest and practical value to the experienced workers; and this, in fairness, seems to have been the primary aim of the authors.

B. N. Cole

\section{Theories of Nuclear Fission}

By L. Wilets. (Oxford Library of the Physical Sciences.) Pp. $x+132$. (Oxford: Clarendon Press; London: Oxford University Press, 1964.) 18s.

THE study of nuclear fission processes has been an active field for more than twenty-five years, but many features still remain to be explored experimentally and discussed theoretically. However, it is a good moment to review the progress made over the past decado.

In his small monograph Dr. Wilets discusses present. day models of fission, including the liquid drop, adiabatic and statistical models. He starts with a clear and concise description of the historically important liquid drop model.
The elegance and precision of this model, which has always appealed to physicists, are exemplified by this treatment. Its limitations are explained and then the discussion moves to more recent models. Rather than discuss them in detail the main features are listed, their importance considered, and the region of validity examined. Probably this style of treatment is essential in a monograph. For the same reason only a limited range of the experimental material is covered, but the most pertinent is used in order to test the models. The mathematical presentation is fairly elementary, making Theories of Nuclear Fission quite easy to read. The pragmatist may feel that this prevents an exact understanding of some parts of the subject. However, to those unfamiliar with the modern developments in the theory of fission, this monograph will be a useful guide, while to those engaged in the field it is a stimulating review. Altogether it is a well-written and well-presented monograph.

P. A. Egelstaft

Theory and Methods of Nuclear Reactor Calculations Edited by G. I. Marchuk. Authorized translation from the Russian. Pp. viii + 199. (Now York: Consultants Bureau, Inc., 1964.) 40 dollars.

THEORY and Methods of Nuclear Reactor Calculations $I$ is a collection of fifteen papers dealing with neutron transport theory, and in particular methods used in the design of reactors, with a group of three papers dealing with topics such as optical model calculations and inelastic scattering of neutrons by iron. It is a translation by the Consultants Bureau, New York, of the original Russian text published in 1962, and edited by Prof. G. I. Marchuk. The translation has been carried out efficiently.

The papers dealing with reactor theory discuss methods which are useful in practical work-they are mainly numerical in character. The first two papers deal with the application of the spherical harmonics method-a method which has been superseded in many cases by the direct numerical integration $S n$ methods of Carlson, which are also discussed. Other subjects of technical interest which are mentioned include: the calculation of the burn-up of poisons in reactors, the thermal neutron spectrum in a homogeneous mixture of moderators at different temperatures and neutron resonance absorption. The paper which deals with the optical model of the nucleus is concerned with the calculation of the transport cross-section-in this paper the choice of various parameters in the model does not seem to be always justifiable. However, it is a useful compilation of papers of interest to reactor physicists.

J. H. TAIT

\section{A Petrography of Australian Igneous Rocks}

By Dr. Germaine A. Joplin. Pp. xiii +210. (Sydney and London : Angus and Robertson, Ltd., 1964.) $63 s$.

THIS short text-book of petrography, presented along genetic lines, is illustrated entirely by descriptions of rock-types occurring in Australia and it has doubtless been written to provide advanced students in Australia with a course of instruction based on local material. The work, however, is well documented and it will be useful elsewhere both as a précis of Australian literature and as a ready source of references to it. The book is in three parts, of which the first is concerned with classification, nomenclature, and textural terms (including brief glossaries of rock names and of textures), the second with the rocks of non-orogenic regions (tholeiites and alkali basalts), and the third with rocks of the orogenic belts (alpine ultramafics, spilites, andesites, granites). Shoshonites and their differentiates occur in both environments. Dr. Joplin has given a lucid exposition of the relationship between magma-type and tectonic environment, and in this connexion her work deserves to be widely read. It contains 39 tables of chemical analyses and is illustrated by about 150 microdrawings. $\quad$ C. F. DAvinson 